\title{
O conhecimento no campo de Engenharia e Gestão do Conhecimento
}

Flávio Marcelo Risuenho dos Santos

Mestre em Engenharia do Conhecimento pela UFSC. Atua como Engenheiro de Equipamentos na PETROBRAS.

Richard Perassi Luiz de Sousa

Doutor em Comunicação e Semiótica pela PUC/SP e professor do Departamento de Expressão Gráfica- EGR/CCE/UFSC, atua na área de Design, cursos de graduação e pós-graduação em Design - EGR/CCE, e no Programa de Pós-graduação em Engenharia e Gestão do Conhecimento EGC/UFSC.

Há uma diversidade de interpretações dos conceitos de termos como "informação" e "conhecimento", implicando as idéias de valor da informação e de valor do conhecimento, com suas características meramente estruturais. Isso dificulta o entendimento e a aceitação de novas áreas de estudos como, por exemplo, a área de Engenharia e Gestão do Conhecimento. Com base na revisão de parte dessa diversidade teórica e de suas críticas, este texto propõe a inclusão e a expansão do termo "cognição" como fator necessário à diferenciação entre os termos "informação" e "conhecimento", no campo de Engenharia e Gestão do Conhecimento. Além disso, são destacadas algumas implicações desse posicionamento epistemológico na revisão dos processos de conversão do conhecimento, previstos por Nonaka e Takeuchi (1997), e de modelagem ao nível do conhecimento, proposto por Allen Newell (1981).

Palavras-chave: Conhecimento; Valor; Gestão do Conhecimento; Engenharia do Conhecimento. 


\section{Knowledge in the field of Knowledge Engineering and Management}

A diversity of interpretations for the concepts of the terms "information" and "knowledge" exists, implicating the ideas of information value and knowledge value, with their merely structural characteristics. This hinders the understanding and acceptance of new areas of study such as Knowledge Engineering and Management. Based on a review of some theoretical diversity and its criticism, this text proposes the inclusion and expansion of the term "cognition" as a necessary factor to differentiate between "information" and "knowledge", in the field of Knowledge Engineering and Management. Besides, some implications of this epistemological positioning are showed through a review in the processes of conversion of the knowledge, presented by Nonaka and Takeuchi (1997), and in the knowledge level modeling proposed by Allen Newell (1981)

Keywords: Knowledge; Value; Knowledge Management; Knowledge Engineering.

Recebido em 19.05.2009 aceito em 05.03.2010

\section{Introdução}

A cognição humana decorre da capacidade desenvolvida por homens e mulheres para a criação ou composição de representações mentais e processos imaginativos, partindo da memória de sensações, sentimentos e idéias. Essas criações ou composições são provocadas por perturbações internas que, em parte, decorrem diretamente dos estímulos recebidos do ambiente no qual os seres humanos estão inseridos.

O conhecimento humano é produto das operações mentais realizadas como testes de correspondência, entre as previsões propostas por modelos mentais, como representações e processos imaginativos, e as respostas ou novas percepções recebidas pelos sentidos, diante da observação e da ação de homens e mulheres no mundo.

As diversas formas de expressão e linguagem permitiram aos homens e mulheres o compartilhamento de conhecimentos, compondo um amplo acervo de conhecimentos comuns que é denominado "cultura". A partir dessa base comum, novos conhecimentos podem e são construídos.

Há milênios, a busca de compreensão sobre as habilidades de comunicação e de construção de conhecimentos tem ocupado muitos 
estudiosos. Durante esse tempo, diversas abordagens teóricas foram desenvolvidas. Alguns termos como: "sinal", "signo", "dados", "mensagem", "informação" e "conhecimento" foram aplicados em diferentes contextos e assumiram diversas significações, sendo que essa diversidade não é constantemente percebida e devidamente considerada.

A indefinição apresentada acima é parcialmente justificada pois, de um ponto de vista estrutural, "signo", "informação" e "conhecimento" (expresso através de uma linguagem), entre outros, podem ser considerados sinônimos, porque são compostos por um elemento percebido pelos sentidos ou pela mente (significante) e associado a uma ou mais idéias ou lembranças (significado). A necessidade de diferenciação, entretanto, foi historicamente determinada por relações de valor e considerações sobre a verdade do conhecimento. Toda associação gera um conhecimento, mas nem todo conhecimento é percebido como verdadeiro ou valoroso. Assim, o termo "conhecimento", na maior parte das vezes, é indicado para designar uma associação considerada verdadeira, enquanto uma associação improvável ou um conhecimento falso são designados como "mito" ou "falácia", entre outros termos possíveis.

Essas questões histórico-conceituais são problemáticas quando esses termos são usados para designar novos campos de estudos e atividades, como "Engenharia do Conhecimento", que procura modelar processos e comportamentos, e "Gestão do Conhecimento", que busca soluções sistêmicas para gerir processos de conhecimento.

A imprecisão filosófica, ontológica e epistemológica acerca do termo "conhecimento" incita questionamentos sobre a Engenharia e a Gestão do Conhecimento, colocando-se em dúvida a pertinência dessas denominações e, conseqüentemente, a possibilidade de existência desses campos de estudos e atividades.

Este texto visa apresentar uma proposta conceitual sobre o conhecimento no contexto da Gestão e da Engenharia do Conhecimento, recuperando teorias e conceituações sobre informação, comunicação, engenharia e gestão.

\section{Abordagem hierárquica DIKW}

Há autores, sendo alguns desses citados a seguir, que se baseiam no conceito de conhecimento expresso por uma relação hierárquica entre dados (Data), informação (Information), conhecimento (Knowledge) e sabedoria (Wisdom), que é conhecida como DIKW, hierarquia da informação, hierarquia do conhecimento ou pirâmide do conhecimento.

A idéia de uma hierarquia entre esses termos já havia sido esboçada nas artes, em um poema de 1934 de Thomas Stearns Eliot (1888-1965) entitulado "The Rock" e na música de Frank Zappa (1940-1993), "Packard Gosse", do álbum "Joe's Garage: Act II\&III" de 1979, e foi consolidada por meio de trabalhos como "Notes on the information concept" (BOULDING, 1955), "Information as a Resource" (CLEVELAND, 1982), "A Guidebook to 
Learning: for a Lifelong Pursuit of Wisdom" (ADLER, 1986), "Management support systems: towards integrated knowledge management" (ZELENY, 1987), "Architect or Bee: The Human Price of Technology" (COOLEY, 1987) e "From Data to Wisdom" (ACKOFF, 1989). O pioneirismo desses trabalhos é apontado em Rowley (2007), Wallace (2007), Frické (2008) e Sharma (2008).

O artigo de Ackoff (1989), "From data to wisdom", muitas vezes, é citado como a origem da DIKW. Apesar de também ter incluído o conceito de "compreensão" situado entre "conhecimento" e "sabedoria", outros autores, como Bellinger; Castro e Mills (2004), contestaram sua pertinência como um nível distinto, entendendo trata-se, na verdade, do processo que permite proceder conversões ou transitar entre os demais níveis. Os conceitos de "sinais" e de "esclarecimento" ou "iluminação", propostos por outros autores, também não foram incorporados a DIKW. Rowley (2007) apresenta as seguintes conceituações propostas por Ackoff (1989):

1. Dados são símbolos que representam propriedades de objetos, eventos e seus ambientes. São produtos de observação e sua utilidade depende da forma em que se encontram. A sua diferença para informação não é estrutural e sim funcional;

2. Informação está contida em descrições, respostas a perguntas que começam com palavras como quem, o que, quando e quantos. Sistemas de Informação geram, armazenam, recuperam e processam dados. As informações são inferidas a partir dos dados;

3. Conhecimento é Know-how, que torna possível a transformação de informações em instruções. O conhecimento pode ser obtido tanto pela transmissão a partir de quem o possui, pelo ensino, ou extraído com base na experiência;

4. Sabedoria é a habilidade de incrementar a eficácia, porque a eficiência é incrementada pela inteligência. Conhecimento adiciona valor, o que demanda a função mental que chamamos de julgamento. Os valores éticos e estéticos em que isso implica são inerentes ao ator e são únicos e pessoais.

O conceito de sabedoria foi pouco desenvolvido em comparação com os demais conceitos aqui apresentados. Além disso, esse termo envolve questões subjetivas e intuitivas que não pertencem ao campo de interesse deste texto. Pois, aqui são considerados prioritariamente os seguintes termos: "dado", "informação" e "conhecimento".

\subsection{Deficiências da DIKW}

Rowley (2007) fez um estudo sobre como esses termos foram tratados por diversos autores, apresentando os acréscimos e processos de 
transformação propostos, e sugeriu referenciá-los como hierarquia da sabedoria, cuja representação seria a de um funil ou pirâmide invertida.

Essa visão sugere que a sabedoria é obtida após o processamento de dados, informação e conhecimento, indicando que esse processo começa com os dados. Todavia, a visão de Rowley (2007) é criticada por Frické (2008), considerando-se os seguintes pontos:

1. A DIKW é embasada em uma visão operacionalista ou positivista e não interpretativa. Assim, os dados têm que ser objetivos, positivos e verdadeiros. As inferências possíveis devem ser diretamente associadas aos fatos positivos e passíveis de serem reduzidas aos dados, para serem consideradas informações válidas. Isso invalida todos os conceitos subjetivos, que não podem ser objetivamente confirmados, relegando-os a condição de informações sem sentido ou sem valor. Isso não prejudica as deduções diretamente lógicas, mas inviabiliza os novos conhecimentos, gerados por inferências indutivas ou abdutivas que, partindo de dados válidos, geram teorias hipotéticas, mas não são necessariamente verdadeiras;

2. A visão operacionalista ou positivista limita o conhecimento possível (Know-how) às deduções ou inferências lógicas, que são extraídas diretamente dos dados da realidade. Assim, dados, informações e conhecimentos são diretamente interligados;

3. Ackoff (1989) considera o conhecimento como know-how expresso por meio de regras. Frické (2008) aponta que, mesmo implicitamente, as regras só podem ser expressas na forma declarativa (know-that). Por isso, adotando uma visão interpretativa, Frické assinala que os dados são informações, mas assevera que nem todas as informações são dados, ou são obtidas diretamente dos dados, destacando que informação e conhecimento são sinônimos;

4. A análise de Frické (2008) aponta que um dos problemas da DIKW é considerar que somente a partir dos dados factuais é possível atingir os níveis mais altos da hierarquia e que os cientistas da informação não querem iniciar uma coleta de dados apenas com a esperança que ao final do processo alguns sejam promovidos a informação;

5. Frické (2008) indica a dedução como princípio de um estudo que deveria começar com uma boa "teoria de questões" para identificar as informações requeridas e a partir delas os dados necessários. Ao contrário da indução proposta pela DIKW, esse autor reconhece que os dados não podem ser o ponto de partida para o conhecimento. Assim, a descrição dos dados não é isenta ou positiva, porque decorre de uma forma padronizada de representação, que foi construída e utilizada 
socialmente com base em um conhecimento pré-existente. 0 conceito fundamental é que o conhecimento produz conhecimento e os dados por si mesmos não geram informação.

\section{Revisão epistemológica}

Para esta revisão, adota-se o pensamento complexo de Morin (1990), que propõe trabalhar com um hiper-paradigma da complexidade, percebendo e concebendo os fenômenos estudados como complexos, para que não sejam mutilados pela simplificação. É necessário atentar-se para as "ilusões" que desviam o espírito do problema do pensamento complexo: crer que a complexidade conduz à eliminação da simplicidade e confundir complexidade com completude, quando o objetivo consiste apenas em obter um conhecimento multidimensional.

Outros referenciais importantes são as idéias de Ludwig Wittgenstein (1889-1951), indicando que os significados das palavras são construídos socialmente, e as idéias de Michael Polanyi (1891-1976), reconhecendo que todo o conhecimento consiste de ou tem suas raízes em atos de compreensão, e que as pessoas conhecem mais do que são capazes de explicitar.

De acordo com as idéias de Polanyi (1983), alguns conhecimentos, ou partes do conhecimento, apenas se manifestam quando surge uma situação na qual sejam necessários. Além disso, não são todos os conhecimentos que podem ser expressos por meio de palavras.

Essa característica do conhecimento como algo que capacita à ação, demandando interação para ser reconhecido, é destacada por diversos autores, mas ainda não existe um consenso sobre quais são as fronteiras do conceito de conhecimento em relação a esse processo de entendimento e capacidade de solução de um problema. De qualquer maneira, há duas questões básicas envolvidas. A primeira indica que o conhecimento não tem expressão própria, necessitando de elementos expressivos ou atitudes para ser percebido. A segunda diz respeito ao valor do conhecimento, indicando que um conhecimento valioso é aquele que se apresenta como solução. Mas, como foi dito anteriormente, do ponto de vista estrutural, um conhecimento propõe associações e não necessariamente soluções.

Há alguns pontos intuitivos de concordância. Para conhecer, é necessário saber associar; para associar, é preciso lembrar; e para lembrar, é necessária alguma forma de representação interior da coisa ausente. As representações permitem o reconhecimento de algo e, também, relaciona suas formas de interação conhecidas.

Segundo Maslow (1908-1970), as interações são motivadas pela busca da satisfação de alguma necessidade (MASLOW, 1943, p. 372) e nosso instrumento de interação é o próprio corpo. O primeiro aprendizado 
está relacionado ao corpo e, a partir dele, os demais conhecimentos são construídos. Para satisfazer às suas necessidades, a mente experimenta e seleciona ações que lhe pareçam mais eficazes, sendo que este é um dos processos de aprendizagem utilizado para a construção de conhecimentos.

De acordo com essa linha de raciocínio, que encontra apoio tanto na Cibernética quanto no Construtivismo, todo o conhecimento é edificado com base nos conhecimentos já possuídos, e essa idéia de posse induz pensar o conhecimento como um objeto, aproximando-o do conceito de informação. Isso reforça a posição de Frické (2008), que indica o conhecimento como decorrente de deduções a partir de teorias anteriores e iguala informação e conhecimento.

O conhecimento só é perceptivo e eficiente quando é denotado por elementos expressivos e se torna atuante por meio de atitudes ou de ações. Por isso, é importante não se perder de vista a característica dinâmica do conhecimento que capacita à ação ou realização de tarefa, o que indica que ele deve possuir tanto características de objeto, quanto de processo.

O conhecimento é algo que está embutido no conjunto das estruturas de representações de um ser. As atitudes do ser permitem que o conhecimento seja reconhecido e se mostre atuante e interagente com elementos do meio ao qual está exposto. A capacidade de trabalhar com essas representações permite, aos seres, projetar os resultados que podem ser alcançados com o repertório conhecido de ações. Assim, é possível, ao ser, escolher as ações que serão executadas para a satisfação de uma necessidade ou de uma meta.

No âmbito dos estudos da Engenharia e Gestão do Conhecimento, é importante considerar os processos de construção, disseminação, utilização e armazenamento de conhecimentos. A criação e a utilização de conhecimentos são fundamentais para o entendimento do conhecimento no contexto da Engenharia do Conhecimento, enquanto que a disseminação e o armazenamento de conhecimentos são, muitas vezes, confundidos com o conceito de informação. Pode-se referenciar como conhecimento, o resultado do acúmulo de experiências de interações entre objetos mentais ou representações e objetos reais, bem como entre as próprias representações mentais.

Desta forma, o conhecimento só pode existir em sujeitos ou entidades que sejam capazes de manipular representações e que possuam uma estrutura cognitiva mínima, capaz de reconhecer estímulos e reagir, de forma coerente, com sua base de conhecimentos. Doravante, esses seres, sujeitos ou entidades, serão denominados de "entes cognoscentes".

De acordo com a visão clássica ocidental, a cognição ou o domínio cognitivo é uma das três partes que compõem a mente. As outras duas partes da mente são a emoção - ou o domínio afetivo - e a volição - ou o domínio conativo. O domínio cognitivo (completo) abrange crenças, aquisição e revisão de crenças, aprendizado, conhecimento e raciocínio.

No livro "Knowledge Management System" (MAIER, 2007), o conhecimento é assinalado como algo que abrange todas as expectativas 
cognitivas, considerando-se as observações que, de modo significativo, foram organizadas, acumuladas e embutidas em um contexto. As experiências, a comunicação e as inferências são instâncias que um ente cognoscente, na posição de ator organizacional, usa para interpretar situações e gerar atividades, comportamentos e soluções, não importando se essas expectativas são racionais ou usadas intencionalmente.

Uma das conseqüências dos argumentos apresentados é que o conhecimento só pode existir em um conhecedor, um ente cognoscente humano, ou não. Além disso, para que esse conhecimento aconteça de modo objetivo é necessário que o ente, ou ator, possua uma capacidade de cognição mínima para aplicar esse conhecimento.

Outra conseqüência, é que a construção de conhecimentos implica na construção de modelos e representações internos ou externos mas, conforme McInerney (2002) adverte, o conhecimento não deve ser confundido com suas representações.

Um dos principais recursos utilizados tanto para a representação, quanto para a disseminação do conhecimento, são as palavras construídas, socialmente, através dos processos de comunicação. Entretanto, a comunicação não se restringe a troca de palavras.

A capacidade de comunicação de um indivíduo aumenta à medida que ele desenvolve novas formas de expressão. Para isso, são usados diferentes sinais que estimulam outros sentidos, como a visão e o tato. Por exemplo, a ordenação da língua foi associada a sinais corporais para compor a Linguagem Brasileira de Sinais (LIBRAS).

Os sinais sonoros, visuais e táteis, entre outros, quando associados a idéias, pensamentos ou lembranças, adquirem significação ou significado, passando a ser identificados como "informação". Uma porção de substância é informada quando expressa um pensamento ou mais. Em seu sentido original, "informar" significa dar forma a alguma coisa. Assim, um pouco da substância "barro" pode ser organizado, ou informado, para expressar um vaso. Nesse caso, o vaso é barro informado que passa a atuar como informação porque comunica, aos espectadores, a idéia de vaso.

A idéia de que o conhecimento é construído por informações, como indica a DIKW, é contrariada na medida em que a informação depende do conhecimento e só pode ser comunicada entre entidades que, antecipadamente, detém conhecimentos sobre o código e, pelo menos, sobre parte do repertório utilizado.

O conceito de informação é ligado à comunicação, indicando que uma mídia é organizada ou informada para comunicar uma idéia, como no exemplo do barro organizado para comunicar a idéia de vaso. O campo semiótico estuda a significação, cujo conceito é necessário à comunicação. A unidade de significação é o signo que, de acordo com Ferdinand de Saussure (1857-1913), reúne um significado (idéia) a um significante (substância) que, no caso da comunicação, necessita ser perceptível. No exemplo adotado, o barro modelado é o significante e a idéia de vaso é o 
significado. Assim, cada sinal capaz de comunicar um significado é chamado de signo.

Por sua vez, Charles S. Peirce (1839-1914) conceitua a parte representativa do signo como "representamen", que é a própria expressão do signo, "aquilo que, sob certo aspecto ou modo, representa algo para alguém". Para esse autor, representar é "estar no lugar de, isto é, estar numa tal relação com um outro que, para certos propósitos, é considerado por alguma mente como se fosse este outro" (PEIRCE, 1977, p. 26). Para se estabelecer uma comunicação, é necessário, portanto, um processo de significação, o qual se estabelece com o uso de um conjunto de sinais representativos ou signos, que são organizados de acordo com regras sintáxicas e semânticas.

Do ponto de vista técnico, considerando-se, especialmente, a codificação e a transmissão de sinais por meio de canais tecnológicos, há o trabalho de Claude E. Shannon (1916-2001) "A Mathematical Theory of Communication" (1948), que ficou conhecido como "Teoria da Informação". O modelo proposto por Shannon (FIG. 1) descreve cinco elementos essenciais ao processo de comunicação: 1- fonte, 2transmissor ou codificador, 3- canal, 4- receptor ou decodificador e 5destinatário

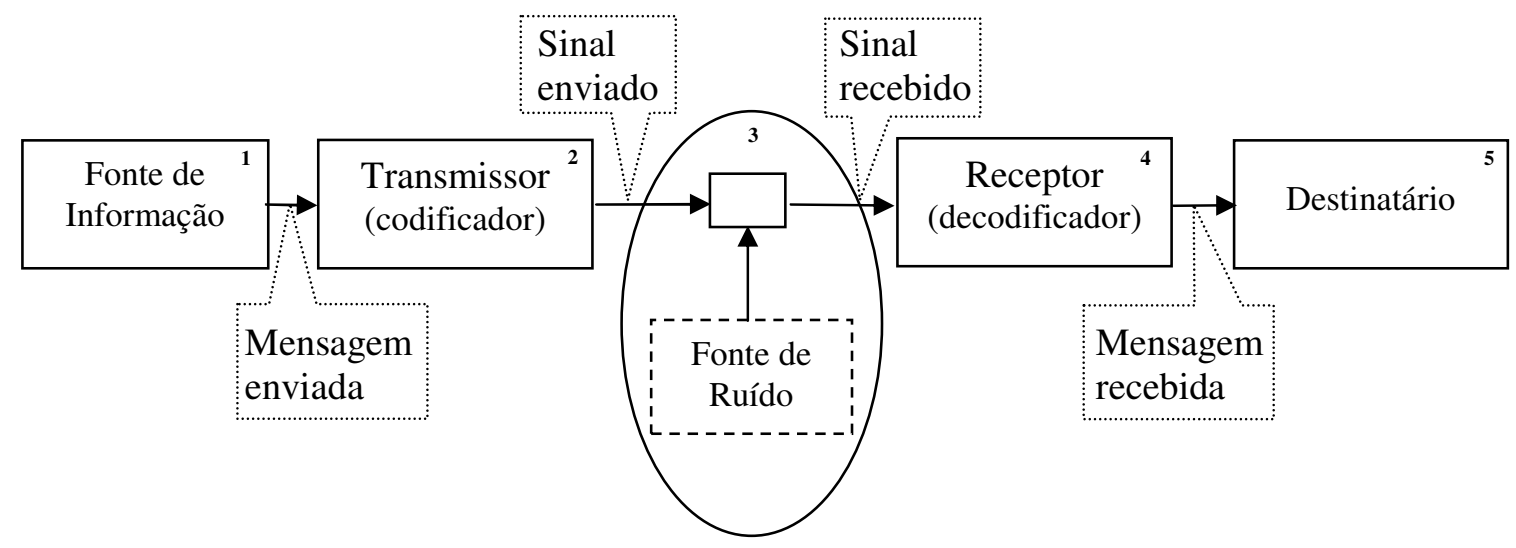

FIGURA 1 - Diagrama esquemático de um sistema de comunicação Fonte: SHANNON, 1948.

O diagrama acima (FIG. 1) indica que o conjunto de sinais enviado pelo canal é emitido e recebido como "mensagem". Nesse sentido, podese entender mensagem como informação enviada por algum canal. Do ponto de vista estrutural, segundo o Dicionário Aurélio (FERREIRA, 1999), mensagem é sinônimo de "comunicação, notícia ou recado verbal ou escrito".

A Teoria da Informação de Shannon prioriza a transmissão de sinais ou mensagens porque não considera, em princípio, a questão semântica. Essa ênfase nas relações quantitativas desvincula os termos informação e mensagem do conteúdo semântico estabelecido no âmbito do destinatário. 
Entretanto, a informação ou a mensagem, disposta no canal, deve ser aceita pelas mídias envolvidas, de acordo com as codificações específicas do sistema. A codificação e o conhecimento previstos no nível técnico dos sistemas são baseados em relações de quantidade. Por isso, os parâmetros de definição da informação na Teoria de Shannon são quantitativos, mesmo com relação às possibilidades de um repertório de signos pré-determinados.

O problema tratado por Shannon é o grau de sucesso da recuperação de uma mensagem gerada por uma fonte de informação para um destinatário e que foi reestruturada por um codificador, em um formato adequado à transmissão, em função das características do canal utilizado.

É importante destacar que, embora uma mensagem tenha a capacidade de transmitir palavras organizadas em frases e em orações, a partir do ponto de vista do emissor, o sucesso da comunicação implica na transmissão do significado previsto para as frases. Para que isso ocorra, é necessário que o destinatário da mensagem tenha a capacidade de interpretá-la de acordo com as intenções do emissor.

Do ponto de vista da interpretação do destinatário humano, a informação é a idéia recebida após a decodificação e a decorrente reconstrução do significante de uma mensagem tecnicamente codificada. Depois de decodificada, uma mesma mensagem pode conter informação em três níveis. O primeiro é o nível sintático - ou pré-denotativo, que trata da organização físico-espacial da mensagem que interfere na significação ou no nível semântico. O segundo é o nível lingüístico - ou denotativo, no qual os sinais, ou significantes, são percebidos como palavras ou como equivalentes a palavras que denotam coisas. O terceiro é o nível pós-denotativo ou conotativo, no qual as palavras ou significantes equivalentes são relacionados para significar idéias que estão além do significado denotativo.

Para exemplificar os níveis descritos acima, é possível considerar-se a expressão "grande homem" em comparação com a expressão "homem grande". Em princípio, há uma distinção relevante no nível pré-denotativo ou sintático, devido à inversão das palavras "homem" e "grande". No nível lingüístico ou denotativo, não há alteração relevante entre as duas expressões, porque ambas reúnem o substantivo "homem" e o adjetivo "grande". No nível pós-denotativo ou conotativo, entretanto, as inversões sintáticas são interpretadas de maneira totalmente diversas, sendo que a expressão "homem grande" é relacionada a um homem de físico avantajado, enquanto a expressão "grande homem" é relacionada a um homem de espírito grandioso.

De um ponto de vista quantitativo, tendo em vista a informação técnica, para a correta recuperação ou decodificação de uma mensagem que contenha alguma das expressões do exemplo anterior, não se pode negligenciar a ordenação dos sinais. Por outro lado, de um ponto de vista qualitativo ou interpretativo, a correta recuperação ou decodificação da 
mesma mensagem irá depender da sensibilidade e do conhecimento do ente cognitivo que a recebe.

Ao aceitar-se que mensagem é informação disposta em um canal de comunicação, é possível considerar que, para ser mensagem, uma informação deve ser tecnicamente compatível com o canal de transmissão. Por outro lado, uma mensagem, para ser informação, deve ser significativa para $o$ ente cognoscente que a recebe. Assim, a elaboração de uma mensagem deve levar em conta as características do canal e como a informação enviada deve ser interpretativamente adequada aos destinatários pretendidos.

De modo prático, o que viabiliza a mensagem são as regras de sintaxe, enquanto a informação é viabilizada pela propriedade semântica. Diante do exposto, as mensagens significativas são aquelas que apresentam informação coerente e valiosa para o ente cognitivo receptor. O valor da informação varia de acordo com a análise qualitativa que é desenvolvida. Mais do que isso, segundo Capurro e Hjorland (2007), algumas teorias chegam a considerar como informação apenas as que atendem a requisitos, como: valor e utilidade; verdade ou correção; novidade; surpresa; redução da incerteza; etc. Esses autores, no artigo "O conceito de informação", destacam que uma das dificuldades existentes para se definir o termo informação advém do fato de este ser um conceito polimórfico e fazem um apanhado de diversos significados a ele atribuído, conforme sua utilização, em vários campos diferentes.

Conforme a Teoria do Significado de Wittgenstein (1996), o significado de um termo ou expressão deve ser inferido de acordo com seu uso, ou melhor, com seu valor de uso. Sob essa perspectiva, a informação de valor para Engenharia e Gestão do Conhecimento é aquela que contribui para o bom funcionamento e desenvolvimento de sistemas e organizações. Entretanto, isso não é uma definição do termo, e sim, uma delimitação do escopo que deve ser refletida por uma qualificação ou classificação apropriada.

Para encontrar a resposta desejada, é importante analisar-se como a informação se comporta nos processos de armazenamento e de disseminação.

Quanto ao armazenamento, alguns autores consideram que a informação, assim como o conhecimento, só pode existir em entes cognoscentes, o que é contestado por Wittgenstein, uma vez que a construção das palavras e de seus significados é um processo coletivo. As palavras, os códigos e, portanto, as significações ou as informações, apesar de serem construídas por entes cognoscentes, têm existência própria no contexto cultural, que é configurado pela mente coletiva do conjunto de entes cognoscentes. As suas características significantes existem e persistem quando registradas em algum meio ou mídia, que também são produtos culturais.

Há a permanência semântica na mídia, que considera os aspectos semânticos no contexto da cultura dos emissores e dos destinatários humanos, mas fora das mentes individuais dos entes cognoscentes. 
Todavia, é interessante considerar-se também a idéia de uma semântica tecnológica, que se estabelece no próprio contexto de codificação da informação presente na mídia. Isso permite que a mídia, por meio de um processo de interpretação tecnológica, reconheça, armazene e transmita a informação mantendo sua estruturação sintática a qual mantém a ordenação da mensagem para posterior decodificação e interpretação semântica por parte de um sujeito cognoscente humano.

O registro de informações permite que mídias perenes possam exercer, parcialmente, os papeis de fonte e transmissor de informações, de forma que o processo de comunicação possa ocorrer sem a presença da fonte de informação original. Desta maneira, a comunicação deixa de ser apenas imediata e passa a ser mediada pelos meios de registro utilizados. De acordo com Maier (2007), isso permite que a comunicação seja uma das vias de construção do conhecimento.

De um ponto de vista estrutural, a informação é conhecimento expresso em um sinal, ou substância. Por isso, muitos autores usam o termo "conhecimento explícito", para designar as informações que participam em atividades de conhecimento, capacitando um ente cognoscente a entender ou agir em algum contexto. Nesse caso, informação e conhecimento são sinônimos, impedindo fazer-se a distinção entre as áreas de Gestão da Informação e de Gestão do Conhecimento. Entretanto, é preciso considerar o valor da informação e o valor do conhecimento, para se compreender que a Gestão do Conhecimento parte da Gestão da Informação, mas deve ir mais além e propor sistemas mentais, sociais ou materiais capazes de selecionar, organizar, desenvolver e dispor as informações e os conhecimentos de valor de acordo com as demandas de uma organização ou cultura institucional. De outra forma, para as áreas de conhecimento, seu objeto de estudo envolve os processos interativos de construção, disseminação e utilização de conhecimentos, os quais normalmente são embasados em processos de armazenamento e recuperação de informações.

Por fim, para se analisar o termo dado é necessário resgatar seu sentido original, de algo entregue ou fornecido. Para Machlup e Mansfield (1983), "dado" é uma coisa fornecida para um analista, investigador ou solucionador de problemas - pode ser números, palavras, sentenças, registros, hipóteses, enfim, qualquer coisa não importando sua forma ou origem. Portanto, o termo "dado" designa os estímulos ou sinais percebidos por um ente cognoscente, humano ou não. Os dados estão no mundo e Ackoff (1989) assinala que a diferença entre dados e informação não é estrutural, mas funcional. Pois, estruturalmente, ambos são sinais significantes, contudo, nem todo dado é considerado como informação de valor.

\section{Implicações relevantes}

Em áreas como Ciência da Informação, Gestão da Informação, Engenharia da Informação ou Gestão do Conhecimento e Engenharia do 
Conhecimento entre outras, os termos "informação" e "conhecimento", são cruciais para definição de seus objetos de pesquisa. Porém, apesar da coincidência estrutural entre aquilo que é designado por ambos os termos, a prática nessas áreas distingue a informação do conhecimento. Entretanto, isso muitas vezes é feito utilizando apenas o critério de valor. Toda informação é produto de um processo de conhecimento expresso em uma mídia, mas nem todo conhecimento é valoroso do ponto de vista dos entes cognoscentes. Por isso, o conceito de "conhecimento" na Engenharia e Gestão do Conhecimento assinala o valor do conhecimento, sendo que a informação em geral é identificada como "dado". Portanto, do ponto de vista funcional, "dado", "informação" e "conhecimento" são distintos de acordo com seu valor diante dos entes cognoscentes. Essa distinção entre informação e conhecimento com base apenas no valor foi duramente criticada por Wilson (2002) em seu artigo "The nonsense of 'knowledge management"', no qual identifica que parte do que hoje é chamado de gestão do conhecimento, trata-se na verdade do resultado de uma estratégia de search and replace marketing, onde o termo informação simplesmente foi substituído por conhecimento.

A necessidade de parâmetros precisos para a distinção desses termos, de acordo com sua função, pode ser percebida em trabalhos como: "Can Information Modelling be Successful without a Common Perception of the Term "Information"? (LEHNER; MAIER, 1997), "Data Is More Than Knowledge: Implications of the Reversed Knowledge Hierarchy for Knowledge Management and Organizational Memory" (TUOMI, 1999a e 1999b), "When knowledge becomes information: a case of mistaken identity" (KAY; CECEZ-KECMANOVIC, 2000), "Knowledge Management: a new idea or a recycled concept?" (SPIEGLER, 2000), "Some Observations on the Semantics of 'Information'" (NEWMAN, 2001), "I = 0 : Information has no intrinsic meaning" (MILLER, 2002), "Informação e Conhecimento: aspectos filosóficos e informacionais" (SIRIHAL; LOURENÇO, 2002), "The nonsense of 'knowledge management"' (WILSON, 2002), "It's tacit knowledge but not as we know it: redirecting the search for knowledge" (CONNELL; KLEIN; POWELL, 2003), "Semantic Conceptions of Information" (FLORIDI, 2005), "O conceito de informação" (CAPURRO; HJORLAND, 2007) e "The Knowledge pyramid: a critique of the DIKW hierarchy" (FRICKÉ, 2008).

Mais do que a revisão de conceitos, entretanto, é necessário o entendimento de como trabalhar, aplicando em informações e conhecimentos de valor, tratamentos adequados aos novos paradigmas que orientam o desenvolvimento das áreas que têm a informação e o conhecimento como objeto de interesse.

Esse processo já está em andamento e um de seus frutos é a nova Engenharia do Conhecimento, na qual o velho paradigma de mineração foi substituído pelo novo paradigma de modelagem, cujas mudanças são bem exploradas em Motta (2001).

É necessário, ainda, desenvolver uma nova terminologia para comunicar o escopo, metodologias, ferramentas e resultados que cada 
área se propõe a alcançar, para que assim seja possível distinguir e compreender os trabalhos elaborados.

Para construir novos termos e significados, não é necessário abandonar a ampla literatura disponível, mas sua utilização demanda um trabalho de re-enquadramento dos termos "informação" e "conhecimento", através de um processo de contextualização, considerando-se a hipótese epistemológica, os aspectos e aplicações do conhecimento e porque ele é abordado nas obras consultadas. (VENZIN; VON KROGH; ROOS, 1999).

Por exemplo, Nonaka e Takeuchi (1997) desenvolveram sua obra reportando a existência de dois tipos de conhecimento. Um dos tipos é o "conhecimento tácito", que é interiorizado, construído com base na experiência, difícil de ser articulado em palavras e, por conseqüência, difícil de ser transmitido. O outro tipo é o "conhecimento explícito", que é fácil de articular e registrar, permitindo sua transmissão a terceiros. A interação dos dois tipos de conhecimento resulta no "Processo SECI", representando quatro modos de conversão do conhecimento: 1socialização, 2- externalização, 3- combinação e 4- interiorização.

A "socialização" prevê a transmissão do conhecimento tácito, fazendo a conversão de tácito para tácito, por meio de processos de compartilhamento de experiências entre os indivíduos de um grupo. Freqüentemente, essa transmissão ocorre por meio da observação, da imitação e da prática.

A "externalização" estabelece a conversão de tácito para explícito, promovendo o processo de articulação do conhecimento tácito em conhecimento explícito, por meio de metáforas, analogias, conceitos, hipóteses e modelos.

A "combinação" caracteriza a conversão de explícito para explícito, através de processos de sistematização de conceitos onde ocorre a junção de conjuntos diferentes de conhecimentos, já explicitados, nos quais as pessoas utilizam meios como documentos, telefone, redes de computadores, conversas e reuniões para classificar,acrescentar,combinar e categorizar conhecimentos diferentes.

A "internalização" promove a conversão de explícito para tácito, por meio de processos de incorporação do conhecimento explícito ao conhecimento tácito.

O foco principal da obra de Nonaka e Takeuchi (1997) é a gestão da dinâmica de criação de conhecimentos relevantes ou de valor para as empresas. Assim, o "conhecimento tácito" é um conhecimento relevante, que ainda não foi devidamente codificado e explicitado em mídia convencional, contendo informação implícita em comportamentos e atitudes, cuja prioridade não é a comunicação. Por sua vez, o "conhecimento explícito" é apresentado como informação de valor bem codificada e comunicada em mídia convencional. Parte da dificuldade de explicitação dos conhecimentos tácitos reside na sua pouca informação ou codificação, que é característica da comunicação estética, a qual é vivenciada, mas não é devidamente interpretada. O conhecimento 
explícito é apresentado como informação altamente codificada, estabelecendo plena comunicação semântica que, além de ser vivenciada, é plenamente interpretada.

Entretanto, a transmissão de informações e conhecimentos no âmbito das organizações, além de considerar a comunicação tácita e explícita, deve considerar também os processos formais e informais de comunicação e educação.

É importante ressaltar que os processos de conversão de conhecimento descritos por Nonaka e Takeuchi (1997) são mais complexos do que o apresentado em seu trabalho. Bandura (1977) e Wenger (1999) tratam da "socialização" ou "processo de aprendizagem social", enfatizando o caráter "informal" do compartilhamento de experiências entre indivíduos componentes de um grupo. Isso é efetivado por meio de comunicação informal decorrente da observação, da imitação e da prática conjunta. A "externalização" é indicada como "produção de informações" relevantes ao negócio, a partir do conhecimento tácito informado em metáforas, analogias, conceitos, hipóteses e modelos. A "combinação" também é indicada como "produção de informações", decorrente do processamento de outras informações, por contextualização e inter-relacionamento. A "internalização" ou "processo de aprendizagem individual" ocorre a partir de informações normalmente chamadas de conhecimento explícito, com extensa base teórica desenvolvida.

A abordagem de Nonaka e Takeuchi (1977) é considerada simplista por ignorar que a correta interpretação da informação demanda um conhecimento tácito. Além disso, desconsidera que a "transmissão" de conhecimentos é realizada por meio de informações. Wallace (2007) analisa as questões epistemológicas inconsistentes na abordagem teórica de Nonaka e Takeuchi (1997).

Os conhecimentos são expressos em informações e, do ponto de vista estrutural, há uma identidade entre o que é percebido como "conhecimento" e como "informação". Porém, há diferenças com relação à natureza e à função de cada um dos objetos designados pelos termos "conhecimento" e "informação".

Nonaka e Takeuchi (1997) não apresentam definições formais para os termos "conhecimento tácito" e "conhecimento explícito" e sua abordagem contradiz as idéias de Polanyi (1983), especialmente, quando esse afirma que há uma dimensão do conhecimento que não pode ser expressa, e que conhecimentos que possuem grande parte situada na dimensão tácita não podem ser comunicados diretamente. Portanto, há conhecimentos que não se apresentam como informações comunicáveis, indicando uma diferença entre conhecimento e informação que vai além da questão do valor.

A crítica ao Processo SECI assinala uma tendência de desviar o foco do conhecimento para o que poderia ser informação, simplificando os processos de construção do conhecimento, que envolvem mais que a troca de informações e de recursos (MEIRINHOS, 2006). Para Wenger 
(1999), a aprendizagem é multidimensional e diversas teorias a abordam por diferentes focos.

Por fim, vale analisar como um sistema informatizado é capaz de possuir conhecimento. Para isso, é necessário que ele possua uma cognição mínima que lhe permita manifestar esse conhecimento. Para Lanz e McFarland (2000), isso demanda uma base de conhecimento, com uma memória simbólica, que armazena informações, e também, demanda um mecanismo de ação que, normalmente, é descrito como know-how. A base de conhecimento e o mecanismo de ação são utilizados pelo sistema para atingir alguma meta conhecida.

Lanz e McFarland (2000) destacam que, nesse sentido, ter knowhow equivale a possuir procedimentos relevantes para a realização de alguma tarefa e que a base de conhecimento pode ser tão simples como um número, resultado de algum processo depositado em uma memória, de modo que esteja disponível para outros processos do sistema.

Os mesmos autores, entretanto, advertem que é difícil para um observador julgar se um sistema é capaz de operar com uma base de conhecimento. Seria como saber diferenciar entre um sistema de atingimento de metas, um sistema perseguidor de metas e um sistema direcionado a metas. No primeiro, a meta só é reconhecida pelo sistema após ser alcançada e, portanto, suas ações não são direcionadas a este fim. No segundo, o sistema persegue uma meta que, no entanto, não está representada no sistema. No terceiro, o sistema possui uma representação da meta a ser atingida e suas ações são direcionadas a este fim. Em todos os casos, o projetista usa seu conhecimento do meio e do sistema para prover um comportamento ao sistema que o conduza à realização de uma meta. Por isso, a diferença entre sistemas é distinta somente para o projetista dos sistemas, apesar de haver a possibilidade de que sejam criados critérios de distinção para um observador externo.

\section{0 conhecimento do "nível do conhecimento"}

A visão de conhecimento apresentada neste artigo está alinhada com a que foi expressa por Newell (1981), em seu artigo "The Knowledge Level" que, apesar de ter contribuído para o surgimento da segunda geração da engenharia do conhecimento, quando houve a mudança do paradigma da extração para a modelagem do conhecimento, (ainda) não foi capaz de provocar o surgimento de uma nova terminologia para esta área.

As idéias que foram expressas por Newell (1981), no artigo "The Knowledge Level", discorrem sobre o nível do conhecimento, adotando principalmente os conceitos de "agente", "metas", "ações", "comportamento", "racionalidade", "conhecimento" e "representação".

O agente é um ente cognoscente capaz de praticar ações e, nesse contexto, possui metas e conhecimentos a partir dos quais atua em seu ambiente, obedecendo ao princípio da racionalidade. Por este princípio, se o agente tem conhecimento que uma de suas ações conduzirá a uma de 
suas metas, então irá selecionar aquela ação. Newell (1981) destaca que o conhecimento e a racionalidade estão intimamente entrelaçados. 0 conhecimento de um agente é definido inteiramente em termos de seu ambiente, que é o objeto de suas metas, e cujas características respondem pelo modo como desenvolve suas ações para atingir essas metas.

As metas são o conjunto de conhecimentos sobre a forma como as coisas devem ficar no ambiente. Sua diferença em relação ao restante do conhecimento reside no fato de influenciar o comportamento do agente de um modo distinto, como aquilo que ele se esforça para realizar. Assim, seu comportamento depende do que sabe, do que quer e dos meios que possui para interagir com o ambiente.

Clancey (1989) considera que o conhecimento, pela visão de um observador, é aquilo que ele atribui a um agente para descrever e explicar as suas interações recorrentes com o seu ambiente. Esse conhecimento deve ser caracterizado de modo completamente funcional, em termos do que permite realizar, e não estruturalmente, em função de objetos físicos com propriedades particulares e relações.

Newell (1981) e outros autores concebem o conhecimento como um potencial para gerar ação, o qual é pressentido ou apenas imaginado como 0 resultado de processos interpretativos, que atuam sobre expressões simbólicas. Falta a percepção de que, neste contexto, o conhecimento não é simplesmente uma coleção de expressões simbólicas com alguma organização estática, porque também requer processos e estruturas de dados.

Para Clancey (1989), a capacidade para executar uma ação não pode ser reduzida a simples descrições dessa ação ao nível do conhecimento. Por isso, para a Engenharia do Conhecimento, uma representação de conhecimento capaz de executar ações requer estruturas e processos e, assim, o conhecimento permanece sempre como algo abstrato e imaterial, não sendo possível retê-lo em um objeto. É importante notar que mesmo o objeto da modelagem no nível do conhecimento não é o conhecimento em si, mas sim o comportamento, ou seja, a interação observada entre um agente e seu ambiente.

O conhecimento serve como a especificação do que uma estrutura simbólica é capaz de realizar e a representação deste conhecimento deve ser expressa em termos de descrições do modelo, e não de instâncias. As representações existem no nível simbólico, como sistemas de estruturas de dados e processos, que realizam um conjunto de conhecimento no nível do conhecimento. Assim, uma representação deve abranger tanto o conhecimento quanto seu acesso. Por isso, pode ser descrita como um sistema para prover acesso a um corpo de conhecimento, isto é, para disponibilizar o conhecimento de uma forma que possibilite a sua utilização para efetuar a seleção de ações a serviço das metas.

É importante evidenciar que o conhecimento necessário para resolver um problema é diferente do processamento necessário para resgatar e usar esse conhecimento em tempo real, o que implica na 
existência de um perfil de custos computacionais para a entrega de partes diferentes do conhecimento total codificado na representação. Isso caracteriza as especificidades das áreas de Engenharia e Gestão do Conhecimento que têm como finalidade, o conhecimento e como objetos de estudo, os sistemas mentais, sociais ou materiais executados por humanos ou meios digitais, capazes de armazenar, resgatar, processar (utilizar), desenvolver e disseminar o conhecimento.

\section{0 conhecimento dos "sistemas baseados em conhecimento"}

Abordar um sistema no nível do conhecimento é tratá-lo como se possuísse alguns conhecimentos e algumas metas e acreditar que ele fará o máximo visando atingir essas metas, escolhendo suas ações de acordo com o princípio da racionalidade.

A análise do conhecimento deve enfocar o resultado da interação do usuário com o sistema em seu ambiente ao longo do tempo e, por isso, o conhecimento não pode ser reduzido ou mapeado apenas sobre uma estrutura física ou um dispositivo isolado.

Segundo Newell (1981), para possuir conhecimentos um sistema deve possuir também racionalidade, pois é difícil conceber qualquer outra forma na qual possa ser dito que um sistema possui conhecimento. A classe de sistemas que têm conhecimento é a daqueles direcionados a metas, e o nível do conhecimento permite a descrição do comportamento desse sistema acima do nível simbólico, sem considerações sobre o que exatamente seja esse sistema. Enquanto o nível simbólico é orientado para o sistema, o nível do conhecimento é orientado para o domínio.

É relevante evidenciar que os sistemas baseados em conhecimento ou knowledge-based system (KBS) operam sem possuir qualquer estrutura física que seja o conhecimento. Para Clancey (1989), suas "bases de conhecimento" são modelos de mundo, codificados em nível simbólico por estruturas de dados e processos. Os processos extraem das estruturas o conhecimento nelas modelados, como uma característica sistêmica do conjunto programa/ambiente/usuário. Além do exposto, um sistema será considerado KBS quando sua principal interação for com um usuário humano.

O KBS deve auxiliar um usuário humano na execução de processos de conhecimento, como se também fosse um agente humano, no sentido que suas ações devem ser percebidas pelo usuário como respostas guiadas por um conhecimento aplicado de acordo com o princípio da racionalidade.

\section{Diferenciando as áreas de informação e conhecimento}

A principal diferença entre focar informações ou conhecimentos é que, no primeiro caso, devem ser enfatizadas as informações que circulam ou devem circular nos processos na organização, e no segundo, os 
conhecimentos que são necessários para a boa execução dos processos ou para promover a inovação.

Há, aqui, três questões que foram desenvolvidas anteriormente. A primeira, diz respeito ao valor da informação e do conhecimento. Estruturalmente, toda informação é expressão do conhecimento, porém, não são todas as informações ou os conhecimentos expressos que são considerados valorosos em uma dada circunstância. A segunda questão considera que, para um observador externo, o conhecimento valioso se manifesta em ações ou atividades também valiosas, de acordo com as circunstâncias. A terceira questão propõe que há conhecimentos valorosos que não ainda não foram expressos como informação passível de ser comunicada, mas que é pressentido ou imaginado em atitudes ou atividades.

Em uma estratégia voltada para o conhecimento, é importante, portanto, mapear 1- o que deve ser conhecido, 2- por quem deve ser conhecido, 3- porque deve ser feito, 4- quando deve ser feito, 5- onde deve ser feito e 6- como deve ser feito. Além disso, o esforço para realizar esse levantamento deve ser ponderado por uma análise de custo e benefício. O conjunto de procedimentos e decisões aqui apresentado é pertinente à gestão do conhecimento.

É importante perceber que existe um crescente interesse sobre gestão do conhecimento. No livro "Sociedade Pós-Capitalista", Peter Drucker (1993) afirma que, neste momento, o único recurso significativo é o conhecimento que capacita à ação, compondo os meios para se obter resultados sociais e econômicos. O valor do conhecimento está diretamente relacionado ao seu potencial de orientar, de forma econômica, o dispêndio de energia para a realização de uma atividade.

A informação exerce papel fundamental nos processos de conhecimento. Por isso, a recuperação da informação é um problema importante, diante do fenômeno da explosão informacional. A grande quantidade de informações que é produzida e disponibilizada dificulta o acesso eficiente, o trabalho de identificação e os processos de utilização. Para que seja capaz de realizar todo o seu potencial, a informação relevante para um problema ou circunstância precisa estar disponível no tempo certo, para a pessoa certa e na forma adequada (MARCONDES, 2001).

Para lidar com o grande fluxo de informações, não basta disponibilizar diversas tecnologias da informação, é preciso criar um ambiente propício a trabalhar com foco no conhecimento, com estratégias e procedimentos suportados por sistemas adequados aos problemas enfrentados. É recomendável que os sistemas baseados em conhecimento, capazes de interagir com o conhecimento disponível e selecionar conhecimentos de valor ou, ainda, gerar conhecimentos de valor circunstanciado, apenas sejam introduzidos quando seus resultados puderem gerar ganhos significativos para a organização.

É preciso gerar informações de valor decorrentes de processos gestores do conhecimento, porque a capacidade de operar com 
informações concisas exige-se ter um conhecimento sobre o conhecimento. O domínio desse conhecimento aplicado ao conhecimento permite a elaboração de sistemas físico-digitais e gerenciais que permitem ao ente cognoscente, com limitada capacidade para operações simultâneas, a resolução de problemas complexos.

\section{Referências}

ACKOFF, R. L. From data to wisdom. Journal of Applies Systems Analysis, New York, v. 16, p. 3-9, 1989.

ADLER, M. J. A guidebook to learning: for a lifelong pursuit of wisdom. New York: Macmillan, 1986.

BANDURA, A. Social learning theory. Englewood Cliffs. New Jersey: Prentice-Hall, 1977.

BELLINGER, G.; CASTRO, D.; MILLS, A. Data, information, knowledge, and wisdom. 2004. Disponível em: <www.systemsthinking.org/dikw/dikw.htm>. Acesso em: 5 fev. 2006.

BOULDING, K. Notes on the information concept. Explorations, Pakistan, v. 6, p. $103-122,1955$.

CAPURRO, R.; HJORLAND, B. O conceito de informação. Perspect. ciênc. inf., Belo Horizonte, v. 12, n. 1, 2007. Disponível em: $<$ http://www.scielo.br/scielo.php?script=sci arttext\&pid=S1413-

99362007000100012\&lng=pt\&nrm=iso > . Acesso em: 1 fev. 2008.

CLANCEY, W. J. The Knowledge level reinterpreted: modeling how systems interact. Machine Learning, United States, v. 4, n. 3-4, p. 285291, Dec. 1989. Disponível em: <http://www.springerlink.com/content/r3j5I76435q5w230/>. Acesso em: 14 jun. 2007.

CLEVELAND, H. Information as a resource. Futurist, Bethesda, Maryland, v. 16, n. 6, p. 34-39, Dec. 1982. Disponível em: <http://hbswk.hbs.edu/pdf/20000905cleveland.pdf $>$. Acesso em: 1 nov. 2008.

CONNELL, N. A. D.; KLEIN, J. H.; POWELL P. L. It's tacit knowledge but not as we know it: redirecting the search for knowledge. Journal of the Operational Research Society, England, v. 54, n. 2, p. 140-152, Feb. 2003. Disponível em: <http://www.palgravejournals.com/jors/journal/v54/n2/full/2601444a.html>. Acesso em: 1 jan. 2009.

COOLEY, M. Architect or bee: the human price of technology. 2nd ed. London: The Hogarth Press, 1987.

DRUCKER, P. Sociedade pós-capitalista. 5.ed. São Paulo: Pioneira, 1993. 
ELIOT, T. S. The rock. London: Faber \& Faber, 1934. Disponível em: <http://www.wisdomportal.com/Technology/TSEliot-TheRock.html>.

Acesso em: 1 jan. 2009.

FERREIRA, A. B. H. Dicionário Aurélio eletrônico: século XXI. Rio de Janeiro: Nova Fronteira, 1999.

FLORIDI, L. Semantic conceptions of information. In: ZALTA, E. N. (Org.). The stanford encyclopedia of philosophy. Stanford: The Metaphysics Research Lab, 2005. Disponível em: $<$ http://plato.stanford.edu/entries/information-semantic/>. Acesso em: 11 nov. 2008.

FRICKÉ, M. The knowledge pyramid: a critique of the DIKW hierarchy. Journal of Information Science, United Kingdon, v. 0, p. 1-12, Oct. 2008. Disponível em: <http://jis.sagepub.com/cgi/rapidpdf/0165551508094050v1 > Acesso em: 11 nov. 2008.

KAY, R.; CECEZ-KECMANOVIC, D. When knowledge becomes information: a case of mistaken identity. In: WORKSHOP ON DATABASE AND EXPERT SYSTEMS APPLICATIONS (DEXA), 11., London, Uk, 2000. Proceedings... Greenwich, Ct: Ieee Computer Society Press, 2000. p. 1128-1133. Disponível

em: $<$ http://ieeexplore.ieee.org/xpls/abs all.jsp?arnumber $=875168>$. Acesso em: 11 dec. 2008.

LANZ, P.; MCFARLAND, D. Philosophical perspectives on representation, goals, and cognition. In: DEAN, J.; RITTER, H.; CRUSE, H. (Comp.). Prerational intelligence: interdisciplinary perspectives on the behavior of natural and artificial systems. Netherlands: Kluwer Academic Publishers, 2000. p. 247-264.

LEHNER, F.; MAIER, R. Can information modelling be successful without a common perception of the term "information"? In: KANGASSALO, $\mathrm{H}$. et al. (Comp.). Information modelling and knowledge bases VIII. Amsterdam, Netherlands: Los Press, 1997. p. 181-198.

MACHLUP, F.; MANSFIELD, U. The study of information: interdisciplinary messages. New York: Wiley, 1983.

MAIER, R. Knowledge management systems: information and communication technologies for knowledge management. 3rd ed. Berlin: Springer, 2007.

MARCONDES, C. H. Representação e economia da informação. Ciência da Informação, Brasília, v. 30, n. 1, 2001. Disponível em: <http://www.scielo.br/scielo.php?script=sci arttext\&pid=S010019652001000100008\&lng=pt\&nrm=iso >. Acesso em: 29 jan. 2008.

MASLOW, A. A Theory of human motivation. Psychological Review, United States, v. 50, n. 4, p. 370-396, Jul., 1943. Disponível em: <http://ovidsp.tx.ovid.com/spb/ovidweb.cgi?\&S=IPBGFPLLNHDDMINENCG 
LOCJLDNFJAA00\&Link+Set $=$ S.sh.40\%7c1\%7cs| 10> Acesso em: 30 jan. 2008.

MCINERNEY, C. Knowledge management and the dynamic nature of knowledge. Journal of the American Society for Information Science and Technology, United States, v. 53, n. 12, p. 1009-1018, 2002. Disponível em:

< http://www.q3.ca/articles/archives/articles/KNOWLEDGE\%20MANAGEME NT.pdf> Acesso em: 30 jan. 2008.

MEIRINHOS, M. F. A. Desenvolvimento profissional docente em ambientes colaborativos de aprendizagem a distância: estudo de caso no âmbito da formação contínua. 2006. 362 f. Tese (Doutorado) - Instituto de Estudos da Criança, Universidade do Minho, Braga, 2006. Disponível em: < http://hdl.handle.net/1822/6219 >. Acesso em: 12 ago. 2007.

MILLER, F. J. I = 0 (Information has no intrinsic meaning). Information Research: an international electronic journal, United Kingdon, v. 8, n. 1, paper n. 140, Oct. 2002. Disponível em: <http://InformationR.net/ir/81/paper140.html> Acesso em: 30 jan. 2008.

MORIN, E. Introdução ao pensamento complexo. 2. ed. Lisboa : Instituto Piaget, 1990.

MOTTA, E. The knowledge modelling paradigm in knowledge engineering. Handbook of Software Engineering and Knowledge Engineering, Singapore, $\quad$ v. 2001. Disponível em: <ftp://cs.pitt.edu/chang/handbook/27.pdf>. Acesso em: 12 jan. 2008.

NEWELL, A. The Knowledge level: presidential address. Ai Magazine, United States, v. 2, n. 2, a. 33, p. 1-20, 1981. Disponível em: < http://www.aaai.org/AITopics/assets/PDF/AIMag02-02-001.pdf>.

Acesso em: 20 jan. 2008.

NEWMAN, J. Some observations on the semantics of "information". Information Systems Frontiers, Netherlands, v. 3, n. 2, p. 155-167, Jun. 2001. Disponível

em: <http://www.springerlink.com/content/q01661p087r53734/>. Acesso em: 20 jan. 2008.

NONAKA, I.; TAKEUCHI, H. Criação de conhecimento na empresa: como as empresas japonesas geram a dinâmica da inovação. Tradução de Ana Beatriz Rodrigues e Priscila Martins Celeste. Rio de Janeiro: Campus, 1997.

PEIRCE, C. S. Semiótica. São Paulo: Perspectiva, 1977.

POLANYI, M. The tacit dimension. Gloucester: Peter Smith, 1983.

ROWLEY, J. The wisdom hierarchy: representations of the DIKW hierarchy. Journal of Information Science, United States, v. 33, n. 2, p. 163-18, Apr. 2007. Disponível em: <http://jis.sagepub.com/cgi/content/abstract/33/2/163 >. Acesso em: 20 jan. 2008. 
SHANNON, C. E. A Mathematical theory of communication. The Bell System Technical Journal, United States, v. 27, p. 379-423 / 623-656, Jul./Oct., $1948 . \quad$ Disponível em: <http://plan9.belllabs.com/cm/ms/what/shannonday/shannon1948.pdf $>$. Acesso em: 23 jan. 2008.

SHARMA, N. The origin of the "Data Information Knowledge Wisdom" hierarchy, 2008. Disponível em: <http://wwwpersonal.si.umich.edu/ nsharma/dikw origin.htm $>$. Acesso em: 23 dez. 2008.

SIRIHAL, A. B.; LOURENÇO, C. A. Informação e conhecimento: aspectos filosóficos e informacionais. Informação \& Sociedade: estudos, João Pessoa, v. 12, n. 1, p. 67-92, 2002. Disponível em: <http://www.ies.ufpb.br/ojs2/index.php/ies/article/viewFile/154/148>.

Acesso em: 9 dez. 2007.

SPIEGLER, I. Knowledge management: a new idea or a recycled concept? Communications of the AIS, United States, v. 3 n. 4, article n. 2, Jun. 2000 Disponível em: <http://portal.acm.org/citation.cfm?id=374521>. Acesso em: 9 dez. 2007.

TUOMI, I. Data is more than knowledge: implications of the reversed knowledge hierarchy for knowledge management and organizational memory. Journal of Management Information Systems, United States, v. 16 n. 3 p. 103-117, winter, 1999a. Disponível em: <http://vnweb.hwwilsonweb.com/hww/results/getResults.jhtml? DARGS= /hww/results/results common.jhtml.21>. Acesso em: 13 nov. 2007.

TUOMI, I. Data is more than knowledge: implications of the reversed knowledge hierarchy for knowledge management and organizational memory. In: ANNUAL HAWAII INTERNATIONAL CONFERENCE ON SYSTEM SCIENCES, 32., Maui, HI, USA, 1999b. Proceedings... Disponível em: $<$ http://ieeexplore.ieee.org/xpls/abs all.jsp?arnumber $=772795>$. Acesso em: 12 nov. 2007.

VENZIN, M.; VON KROGH, G.; ROOS, J. Future research into knowledge management. In: VON KROGH, G.; ROOS, J.; KLEINE, D. (Comp.). Knowing in firms: understanding, managing and measuring knowledge. Thousand Oaks, Ca, USA: Sage Publications, 1999.

WALLACE, D. P. Knowledge management: historical and cross-disciplinary hemes. Westport: Libraries Unlimited, 2007.

WENGER, E. Communities of practice: learning, meaning, and identity. Cambridge University Press, 1999.

WILSON, T. D. The nonsense of 'knowledge management'. Information Research: an International Electronic Journal, United Kingdon, v. 8, n. 1, paper n. 144, Oct. 2002. Disponível em: <http://informationr.net/ir/81/paper144.html >. Acesso em: 30 jan. 2008. 
WITTGENSTEIN, L. Investigações filosóficas. 2. ed. Petrópolis: Vozes, 1996.

ZAPPA, F. Packard gosse. In: Joe's Garage: Act II\&III, 1979. (Álbum).

ZELENY, M. Management support systems: towards integrated knowledge management. Human Systems Management, Netherlands, v. 6, n. 7, p. 59-70, 1987. 